\title{
Poder, cultura e texto em Roland Barthes
}

Robert Ponge

Em 1977, três anos antes de seu falecimento acidental, ao delinear, em Leçon, a síntese e o balanço de cerca de trinta anos de atividade teórica e crítica, Roland Barthes fez questão de afirmar que, para ele, nào poderia existir outro eixo de trabalho senào o político; que, apesar das mudanças, dos "deslocamentos" que tinham marcado seu itinerário intelectual, este fora percorrido "conservando o mesmo objeto, político - pois nào existe outro"1. Havia, com efeito, uma relaçào permanente de Barthes com a politica.

\section{Uma particularidade e uma obsessão}

Relação permanente de Barthes com a política, mas também muito particular; pois, como ele próprio precisou, "no meu discurso escrito, nào há discurso político no sentido temático da palavra: nào trato de temas diretamente políticos, de 'posiçòes' políticas" . Os caminhos de sua reflexào passavam pela delimitaçào de um campo de trabalho que fosse político sem sê-lo "diretamente": a linguagem. Aí residia sua particularidade: "Eu, coloco sempre os problemas em termos de linguagem. É meu próprio limite” (GV, p. 336).

A atividade política de Barthes acontecia por fora da atividade militante, nào se exercia sobre a questào social; limitada ao trabalho sobre a linguagem, fugia do discurso político. Sua relaçào com a coisa política era, portanto, "discreta". Uma relaçào discreta, mas, contudo, "obcecada" (GV, p. 206) pela presença de um objeto,

Licenciado, pós-graduado (DES e agrége) pela Universidade de Paris (França), doutor em Letras pela Universidade de São Paulo, Robert Ponge é Professor Titular de Literatura Francesa e Francófona do Instituto de Letras da Universidade Federal do Rio Grande do Sul - UFRGS, em Porto Alegre.

Este artigo representa um momento de uma pesquisa mais ampla sobre a ética política de Roland Barthes.

'BARTHES, Roland. Leçon. Paris: Le Seuil, 1978. p. 33. Doravante referido através da abreviação "Lç", seguida da indicação da página. A tradução para o português desta e das demais citações foi feita por mim.

'Idem. Le Grain de la voix - Entretiens 1962-1980. Paris: Le Seuil, 1981, p. 252. Doravante referido através da abreviação "GV". 
de um inimigo: o poder. Em Le Grain de la voix, Barthes definiu-se como "uma sensibilidade obstinada, [...] extrema" em relação ao poder ou, mais precisamente, "um fundo inalterável de anarquismo, no sentido mais etimológico da palavra" (GV, p. 253), isto é, uma aspiração à ausência de todo e qualquer poder. Aspiraçào que expressava, ao nível de sua atividade, através da denúncia de todas as formas de presença do poder. Era a sua guerra contra o poder. Pode-se, sem risco de trai-lo, estender a seus outros trabalhos o tema que definiu para Leçon e dizer de toda sua obra: "É, com efeito, de poder que se tratará aqui, indireta mas obstinadamente” (Lç, p. 10).

\section{A presença do poder na sociedade}

\section{Poder e sociedade de classes}

Roland Barthes sempre reconheceu ter uma "sensibilidade" de esquerda, uma certa familiaridade com a simpatia pelo marxismo. É no quadro desta tradiçào que analisa a sociedade contemporânea como "dividida [... pelas] classes sociais, aquelas que o marxismo e o socialismo nos ensinaram a reconhecer". De maneira clássica, distingue as "três classes típicas": a classe dominante, a burguesia; a classe dominada, o proletariado; e a classe média ou intermediária, a pequena burguesia. ${ }^{3}$

Ele sabe que essa ordem burguesa está alicerçada sobre um Estado, um Direito e, portanto, sobre a violência das instituiçòes criadas para fazê-los respeitar, para servir-lhes de pilar: "Há uma violência da lei, das leis, uma violência das polícias, do Estado, do direito" (GV, p. 287). Mas pensa que a sociedade burguesa não se mantém somente graças à eficácia dos aparelhos coercitivos da classe capitalista, apoiando-se, sustentando-se também na divulgaçào, na disseminação e na reproduçào de valores, de conceitos, de imagens, de mitos, de interpretaçòes - o que, desde Karl Marx, convenciona-se chamar de ideologia da classe dominante. Em decorrência, Barthes coloca no centro de seu pensamento a importância fundamental dos processos ideológicos, superestruturais, no mundo contemporâneo. Por outro lado, ele também sensibiliza-se à idéia de que, sem cessar de ser determinado pelas divisões de classes, o mundo conheceu profundas modificaçòes:

"Hoje [1962], nossa sociedade é particularmente difícil de entender. [...]. Os problemas de classe tornaram-se impensáveis com os termos empregados há

\footnotetext{
'Idem. Le Bruissement de la langue. Paris: Le Seuil, 1984, p. 110. Doravante referido através da abreviação "BI".
} 
cinqüenta anos. Vivemos ao mesmo tempo uma sociedade de classes e uma sociedade de massa" (GV, p. 16).

Barthes entende que se trata de uma sociedade de classes que, culturalmente, é de massa. Isto é, para ele, a dominação dos meios modernos de comunicaçào de massa sobre a sociedade faz com que vivamos na idade da cultura de massa, onde os "grandes problemas" (portanto, inclusive aqueles de classes) não colocam-se somente no terreno que lhes é próprio e, portanto, enquanto "problemas diretos", mas também se verificam no domínio da cultura, onde (da mesma forma que em outras esferas) podem aparecer sob uma forma indireta, "embaralhada" (GV, p. 16): na sociedade de massa, os traços, as características da sociedade de classes expressam-se, cada vez mais e sob formas variadas, no terreno da cultura.

\section{A cultura de massa}

O que, para Barthes, caracteriza a cultura de massa? É o fato de ser produzida e existir para todos, ou seja, explica ele, o fato de que, nos anos sessenta e setenta, "a cultura está aí, por toda parte e para todos" (BL, p. 109): toda a cultura é "de massa", colocada em livros, em discos, em filmes, em programas de televisào, em fitas de vídeo, etc.; todo mundo sabe ler; todo mundo tem em casa um toca-discos, uma TV, um gravador, um vídeo-cassette, etc.; ${ }^{4}$ a cultura está ao alcance da mão, basta girar o botào ou comprá-la, com um preço que a grande produçào industrial torna acessível e que é ainda mais reduzido pelos hipermercados que suplantam, cada vez mais, as pequenas lojas. Aparentemente, todas as barreiras cairam, somente a escolha individual, as preferências pessoais fazem com que o torneiro mecânico da fábrica de automóveis Renault compre um disco de Mireille Mathieu ou dos Rolling Stones em vez da Nona de Beethoven. Tudo está ótimo. Enfim, o homem tem acesso à cultura. É o regime da "democracia cultural":

Todo mundo, na nossa França de hoje [1971], pode entender um programa de televisào, um artigo do [diário] France-Soir, a ordem dos pratos de uma refeiçào de festa; mais ainda, pode-se dizer que, afora um pequeno grupo de intelectuais, todo mundo consome esses produtos culturais: a participaçào objetiva é total; e,

${ }^{4}$ Aqui, é necessário lembrar-se que, mesmo se algumas vezes amplia sua análise além das fronteiras da França, Roland Barthes restringe-se, em geral, em falar da mesma, sem ignorar que o que diz pode aplicar-se, numa certa medida, a outros países (países da América do Norte, do Mercado Comum Europeu) ou não. Quanto ao Brasil e aos outros paises do chamado Terceiro Mundo, ele não fala a respeito. 
caso se definisse a cultura de uma sociedade pela circulaçào dos símbolos que nela acontece, nossa cultura apareceria tào homogênea e cimentada como a de uma pequena sociedade etnográfica” (BL, p. 113).

Porém, na verdade, a unidade cultural é somente aparente, formal:

"A cultura é, de uma certa maneira, o campo patólogico por excelência no qual se inscreve a alienaţão do homem contemporáneo" (BL, p. 109, grifado por Barthes).

Esta alienação é "dupla", pois fruto de uma contradição cujos dois pólos sào, de um lado, a "imobilidade trágica da cultura" e, do outro, a "separaçào dramática das linguagens” (BL, p. 111).

\section{A "imobilidade da cultura de massa"}

Para ter uma idéia dessa "imobilidade", é preciso, primeiro, entender qual é a natureza da cultura. Na época de Barthes, era, dentro da esquerda, sabido e reconhecido, que, conforme ensinara Karl Marx, as idéias dominantes são as da classe dominante, que a burguesia modela a sociedade segundo seus interesses e que o capital imprime sua marca sobre todas as coisas e relaçòes. Conseqüentemente, no ver de Barthes, "toda nossa cultura é burguesa", avaliaçào que, de tào repetida, batida, se tornou "um truísmo cansativo" (BL, p. 107). Mas, Barthes insiste que, nào obstante, é necessário dela partir e compreendê-la plenamente: ter consciência do caráter burguês da cultura e de sua capacidade de ser invasora, onipresente, quase pegajosa. Pois, queira-se ou nào, nào se consegue livrar-se dela; talvez até esteja onde menos se suspeita: "A cultura está em nós: em nossa sintaxe, na maneira como falamos, até talvez numa parte de nosso prazer" (GV, p. 153).

Como, porém, conciliar o caráter burguês da cultura com outra afirmaçào de Barthes segundo a qual "a cultura de massa é pequeno-burguesa"? É que ela é pequeno-burguesa pela classe que é sua criadora e pelas formas através das quais é elaborada. Mas, é burguesa no que toca à seus modelos, seus valores fundamentais, suas referências. É uma cultura feita pela pequena-burguesia, a partir da cultura burguesa, através de um processo pequeno-burguês de "degradaçào" da mesma. Barthes é muito claro a este respeito; é melhor deixá-lo falar:

"Das três classes típicas, é hoje a classe intermediária [...] que mais busca elaborar uma cultura original, no sentido de que seria a sua cultura: é incontestável que um trabalho importante é desenvolvido ao nível da cultura dita de massa (isto é, da cultura pequenoburguesa) - e por isso seria ridiculo virar-- the as costas. Mas segundo que caminhos? Pelos caminhos já conhecidos da cultura burguesa: é tomando e degradando os modelos (os patterns) da linguagem burguesa (suas narrativas, seus tipos de raciocínio, seus valores 
psicológicos) que a cultura pequeno-burguesa se faz e se implanta. A idéia de degradação pode parecer moral, oriunda de um burguês que lamenta a excelência da cultura passada: dou-lhe, ao contrário, um conteúdo objetivo, estrutural: há degradaçào porque nào há invenção; os modelos sào repetidos no mesmo lugar, achatados, pelo fato de que a cultura pequeno-burguesa [...] exclui até a contestação que o intelectual pode trazer à cultura burguesa: é a imobilidade, a submissão aos estereótipos (a conversão das mensagens em estereótipos) que define a degradaçào" (BL, p. 110-111, grifado por Barthes).

A banalidade, a falta de imaginação, a ausência de originalidade reinam. $O$ resultado é uma "imitaçào irrisória", uma reproduçào "em farsa" da cultura burguesa. Nào há invençào, novidade, mas imobilidade da cultura.

\section{A "separação das linguagens"}

A cultura está unificada na e pela cultura de massa, mas Barthes assinala que essa unidade é uma "ilusào", pois, sob a aparência da unidade da cultura, existe a guerra das linguagens:

"[...] a cultura é um campo de dispersão [...] das linguagens.

Na nossa cultura, na paz cultural, a Pax culturalis à qual estamos submetidos, há uma guerra sem trégua e eterna das linguagens: nossas linguagens excluem-se umas às outras; numa sociedade dividida (pela classe social, o dinheiro, a origem escolar), a própria linguagem divide” (BL, p. 108, grifado por Barthes).

Como? Por quê? Durante um dia inteiro, no trabalho, no restaurante, em casa, lendo o jornal, escutando os colegas ou os vizinhos de mesa, olhando diferentes programas na televisào, conversando em família, vendo, sem prestar atençào, a publicidade no metrô, somos os receptores de "linguagens" diferentes. Ora, comenta ele, "há sempre na cultura uma porçào de linguagem que o outro (portanto eu) nào entende" (BL, p. 108), acha desprovido de interesse ou, simplesmente, irritante. Pois bem, a incompreensào, a ausência de interesse, a irritaçào "sào os nomes diversos

${ }^{5} \mathrm{GV}$, p. 146. Para a idéia de repetição em farsa, Barthes inspirou-se obviamente na observação com que Marx abre o 18-Brumário de Louis Bonaparte: "Hegel faz, em algum lugar, a observação que todos os grandes acontecimentos e personagens históricos repetem-se, por assim dizer, uma segunda vez. Esqueceu de acrescentar: a primeira vez como tragédia, a segunda como farsa. Caussidière para Danton, Louis Blanc para Robespierre [...]. E constatamos a mesma caricatura nas circunstâncias em que apareceu a segunda edição do 18-Brumário" (MARX, Karl. Le 18Brumaire de Louis Bonaparte. In: MARX, Karl; ENGELS, Friedrich. Euvres choisies, en trois volumes. Vol. 1. Moscou: Éd. du progrès, 1976. p. 414). 
da secessào das linguagens. O resultado é que essa secessào nào separa somente os homens entre si, mas cada homem, cada indivíduo é, ele próprio, dilacerado" (BL, p. 109). Barthes infere daí que a humanidade vive uma guerra da linguagens, "uma guerra dos sentidos" (BL, p. 111), na qual das linguagens excluem-se umas às outras:

"Estamos atualmente na guerra, nào do sentido (uma guerra para abolir o sentido), mas dos sentidos: significados enfrentam-se, munidos de todas as espécies de armas possíveis (militares, econômicas, ideológicas, até mesmo neuróticas)" (GV, p. 120-121).

A divisào das linguagens e da linguagem é "um sinal da alienaçào de nossa sociedade" (GV, p. 145). Para Barthes, esses dois elementos sào também um sinal e a conseqüência da presença permanente, penetrante, invasora do poder, dos poderes, na cultura, nas linguagens.

\section{Poder e linguagem}

Em Leçon, Barthes define o poder como a açào da "libido dominand?" (o desejo ou vontade de dominação), a atividade do "querer-agarrar". Descreve, em seguida, as diversas etapas da evoluçào de seu pensamento em relaçào às formas de existência e de manifestaçào do poder.

Inicialmente, Barthes lembra que toda uma época, da qual conheceu e compartilhou o final, tratou o poder "como se fosse um: de um lado os que o detêm, do outro os que nào o têm" e como se fosse "um objeto exemplarmente [isto é, unicamente] político" (Lç, p. 10-11). Aqui, ele refere-se à tradição elaborada pelos clássicos do marxismo (sobretudo Marx, Engels, e, depois deles, Lenin, Rosa Luxemburgo, Trotski e alguns outros). Segundo a mesma, o poder procede diretamente da divisào da sociedade em classes e se cristaliza num aparelho de Estado de conteúdo fundamentalmente repressivo e burocrático, instrumento da supremacia da classe dominante. Na mesma ótica, a tomada do poder pelo proletariado e a destruiçào do aparelho de Estado burguês abririam o caminho para o definhamento do Estado.

Em seguida, seus contemporâneos e ele acreditaram que o poder "é também um objeto ideológico que se insinua lá onde nào é imediatamente percebido, nas instituiçòes, no ensino, mas, em suma, que é sempre um” (Lç, p. 11). Reconhece-se, aqui, a influência das inovaçòes de Louis Althusser, que considerou "indispensável acrescentar alguma coisa à definiçào clássica do Estado como aparelho de Estado" :

\footnotetext{
"ALTHUSSER, Louis. "Idéologie et appareils idéologiques d'État (notes pour une recherche)". Ia Pensée, n 151. Paris: mai juin 1970. p. 11.
} 
a teoria dos diversos aparelhos ideológicos de Estado (religioso, escolar, familiar, de informaçào, etc.).

Mas, no final de sua caminhada, Barthes descobriu que o poder revelava-se "plural no espaço social [...e] perpétuo no tempo histórico" (Lç, p. 12). Foi-lhe forçoso constatar, por um lado, que nào existe apenas um poder, mas poderes:

Em toda parte, de todos os lados, chefes, aparelhos enormes ou minúsculos, grupos de opressào ou de pressào; em toda parte, vozes 'autorizadas', que se autorizam a fazer ouvir o discurso de todo poder [...]. Adivinhamos, entào, que o poder está presente nos mecanismos mais sutis da troca social: nào somente no Estado, nas classes, nos grupos, mas ainda nas modas, nas opiniòes correntes, nos espetáculos, nos jogos, nos esportes, nas informaçòes, nas relações familiares e privadas e até mesmo nas pressòes liberadoras que tentam contestá-lo (Lç, p. 11).

Por outro lado, que o poder é

perpétuo no tempo histórico: expulso, extenuado aqui, reaparece acolá; nào definha jamais: façam uma revoluçào para destruí-lo, imediatamente voltará a renascer, a germinar no novo estado de coisas (Lç, p. 12).

Barthes explica essa existência múltipla e permanente do poder pela sua presença na linguagem. Há aí, senão uma influência de Michel Foucault, pelo menos uma certa convergência entre ambos. Para Foucault, "o discurso está na ordem das leis", dirigido, enquadrado pelas instituiçòes vigentes: sua produçào é vigiada, "controlada, selecionada, organizada e redistribuída por um certo número de procedimentos", internos c externos, de controle e de delimitaçào. Estes reservamthe e ao mesmo tempo impòem-lhe um lugar "que o honra, mas que o desarma"7 simultaneamente, lhe atribuem um poder que procede das leis, das instituiçòes do poder. Na mesma linha, para Barthes, a explicação da resistência e da ubiqüidade do poder é que

FOUC.AULT, Michel. LOOrdre du distours. Paris: Gallimard, 1971. p. 9 -11 e 9. 
o poder é o parasita de um organismo trans-social, ligado a toda a história do homem, e nào somente à sua história política, histórica. Este objeto, no qual o poder se inscreve, desde todo o sempre humano, é: a linguagem — ou, para ser mais preciso, sua expressão obrigatória: a língua (Lç, p. 12).

Entende-se melhor a guerra cultural, a guerra das linguagens, a guerra dos sentidos. Nessa situação, o que fazer?

\section{O engajamento}

Neste mundo, que o poder molda à sua imagem, penetrando em todos seus lugares e recantos, o que fazer? Será que o intelectual pode se engajar e como pode fazê-lo?

Nos anos cinqüenta, Barthes responde positivamente à questào. Definindo o intelectual como "uma consciência, ou melhor ainda: um olhar", the atribui a tarefa de desvendar, fazer vir à tona, revelar a presença da história e do poder num objeto - a linguagem: lhe propôs construir "uma ciência dos signos" que fosse um instrumento de crítica social, uma "semiologia geral de nosso mundo burguês". Mostrou o caminho, produzindo, entre outros, Le Degré zéro de l'écriture e Mythologies.

No fim dos anos 60, as preocupaçòes centrais de Barthes conheceram uma certa mudança, sua semiologia

coloriu-se diferentemente, embora conservando o mesmo objeto, político - pois não existe outro. [...].

$[\ldots .$.$] a semiologia de que falo voltou, entào, ao Texto (Lç, p. 33-34).$

A "Apresentação" de fevereiro de 1970 a Mythologies indicava uma direçào: preconizava a necessidade e a possibilidade da busca de uma "certa liberaçào do significante" (My, p. 7). A primeira manifestaçào importante dessa mudança data do mesmo ano: foi L'Empire des sens, ensaio que "situa-se em um momento de minha vida quando senti a necessidade de entrar inteiramente no significante" (GV, p. 83).

\footnotetext{
"BARTHES. Mythologies. (1957). Paris: Le Seuil, coll. "Points", 1970. p. 189. Doravante referido através da abreviação " $\mathrm{My}$ ".
} 


\section{A entrada no significante}

Tratava-se, da parte de Barthes, "nào de uma volta atrás", mas de um "deslocamento" (GV, p. 84), cujas causas explicou em vários lugares. Do ponto de vista mais geral, "esse deslocamento ocorreu porque a sociedade intelectual mudou, nem que fosse apenas através da ruptura de maio de 68". Mais precisamente, isto significa duas ordens de elementos: "Por um lado, trabalhos contemporâneos modificaram e modificam a imagem crítica do sujeito social e do sujeito falante". Por outro lado, o próprio poder mudou; não é mais único, proliferou, propagou-se:

[...] ficou visivel que, na medida em que os aparelhos de contestação se multiplicavam, o próprio poder, enquanto categoria discursiva dividiase, estendia-se como água que corre por tudo, cada grupo de oposição tornando-se, por sua vez e à sua maneira, um grupo de pressão e entoando, em seu próprio nome, o discurso mesmo do poder, o discurso universal: uma espécie de excitação moral tomou conta dos corpos políticos, e, mesmo quando se reivindicava a favor do gozo, era num tom cominatório. Viu-se, assim, a maioria das liberaçòes postuladas, as da sociedade, da cultura, da arte, da sexualidade, enunciarem-se sob formas de um discurso do poder: vangloriava-se em fazer aparecer o que tinha sido esmagado, sem ver que, desta maneira, esmagava-se em outro lugar (Lç, p. 33-34).

O "inimigo capital" continua a ser, em termos gerais, "a norma burguesa" (My, p. 8); porém, Barthes está agora consciente de que o poder penetra em todos os lugares e, sobretudo, em todas as linguagens. Manifesta-se, sem dúvida, sob a forma dos discursos do poder, a "linguagem encrática (aquela que se produz e se propaga sob a proteçào do poder)"'. Mas, sobretudo, discretamente, sem ninguém estar consciente, incansavelmente, sem fallhas, o poder impregna a língua, gerando "discursos de poder" que sào ainda mais nocivos, porque se ignora ou se subestima sua existência e seus perigos: "O poder (a libido dominandi) está aí, oculto em todo discurso que se produz, mesmo que seja a partir de um lugar exterior ao poder" (Lç, p. 10).

Diante desta nova situaçào, Barthes entende que as formas de seu combate de sempre contra o poder devem evoluir e precisa seu alvo:

\footnotetext{
"Idem. Le Plaisir du tex\%e. Paris: Le Seuil, coll. "Tel quel", 1973. p. 66. Doravante referido através da abreviação "PT".
} 
Alguns esperam de nós, intelectuais, que nos agitemos a todo momento contra o Poder; mas nossa verdadeira guerra está em outro lugar; é contra os poderes, e não é um combate fácil (Lç, p. 11-12).

Ele também precisa os terrenos, os meios, os instrumentos, as armas desse combate. Inicialmente, a crítica ideológica e semiológica "precisa ser tornada mais sutil" (My, p. 9). No que lhe toca, nào poderia mais se "contentar em colocar em relaçào formas com conteúdos ideológicos como o f[e]z em Mythologies. [...]. Agora é necessário levar o combate mais longe, [...]" (GV, p. 84). Mas, aonde?

Barthes alerta contra a tentaçào - à qual numerosos elementos de vanguarda cederam - de lançar-se em tentativas de criaçào de uma contra-cultura ou de uma não-cultura:

[...] em um certo sentido, tudo é cultural, c é impossivel praticar uma não-cultura. A cultura é uma fatalidade à qual estamos condenados. Assim, desenvolver uma ação contra-cultural radical não passa de um mero deslocamento da linguagem [...]. Uma atitude de destruição radical da cultura parece-me, portanto, irrefletida, relativamente ineficaz e com valor apenas expressivo (GV, p. 145).

Nào somente está condenada ao fracasso, mas, ao nível da linguagem, revelase um profundo engodo:

Não há nenhum lugar sem linguagem: não se pode opor a linguagem, o verbal e até mesmo o verboso a um espaço puro, digno, que seria o espaço do real e da verdade, um espaço fora da linguagem $[\ldots A]$ linguagem perpassa todo o real; não há real sem linguagem. Qualquer atitude que consiste em se resguardar da linguagem, atrás de uma não-linguagem ou de uma linguagem pretensamente neutra ou insignificante, é uma atitude de má fé. |.... Não podemos passar para o não-discurso porque o nào discurso não existe; mesmo as atitudes mais terroristas, mais extremistas, prestam-se à recuperaçōes muito rápidas (GV, p. 153-154).

Se é impossivel colocar-se fora da cultura, fora da linguagem, o único combate possível está no seu seio: "[...] penso que nào há outra soluçào senào aceitar essa fatalidade da cultura. É necessário, portanto, trabalhar para a sua destruiçào ou para a sua mutaçào desde dentro" (GV, p. 145). (Que tipo de trabalho é possível? A funçào do intelectual "ser de linguagem" - é "criticar a linguagem burguesa sob o próprio reino da burguesia; deve ser, ao mesmo tempo, um analista e um utopista, representar simultaneamente as 
dificuldades e os desejos loucos do mundo [...]" (GV, p. 187). É um trabalho que "nào é de politizaçào, mas de crítica dos sentidos, de crítica do sentido" (GV, p. 147). Como? Entrando "inteiramente no significante", o que implica "no recuo do significado, mesmo que este fosse altamente estimável por sua natureza política":

É necessário agora levar o combate mais longe, tentar fissurar não os signos, significantes de um lado, significados de outro, mas a própria idéia de signo: operação que se poderia chamar de semioclastia.

[...]. É necessário, em nosso ocidente, em nossa cultura, em nossa língua e em nossas linguagens, empreender uma luta de morte, uma luta histórica com o significado (GV, p. 83-84).

\section{Niilismo, destruição do significado e texto}

O estado de espírito, a filosofia, que inspira esse trabalho, orienta seus meios, ć o niilismo. Um niilismo muito particular, que busca a "destruiçào do sentido" (ibidem), a destruiçào do significado, a destruiçào do discurso ocidental. A idéia de destruir é, para Barthes, sinônimo de "perturbar, subverter" (GV, p. 91) - termos que passa a preferir porque sào mais fiéis à atitude geral que comanda seu procedimento, marcado pela reflexividade, pela recusa da repetiçào, pela busca do deslocamento permanente:

"A única subversào possivel em matéria de linguagem é deslocar as coisas. A cultura burguesa está em nós: em nossa sintaxe, na maneira como falamos, até talvez numa parte de nosso prazer. Nào podemos passar para o não-discurso porque 0 nào-discurso nào existe; mesmo as atitudes mais terroristas, as mais extremistas prestam-se à recuperaçòes muito rápidas. O único combate que sobra nào é franco, mas no mais das vezes amortecido, insidioso. Nào é sempre triunfante, mas deve tentar deslocar as linguagens, tentar criar uma nova tipologia da linguagem com a linguagem burguesa, com suas figuras de retórica, com suas maneiras sintáxicas, com seus valores de palavras: um espaço novo onde o sujeito da escritura e o da leitura nào tem exatamente o mesmo lugar. É todo o trabalho da modernidade" (GV, p. 153-154).

Esse espaço novo - onde se pode "entrar intciramente no significante" (GV, p. 83), onde se pode subverter, perturbar, onde a língua pode ser "combatida, desviada: nào pela mensagem da qual é o instrumento, mas pelo jogo das palavras do qual é o palco", onde se pode "trapacear com a língua, trapacear a língua" - é a literatura ou escritura ou texto ("Posso [...] dizer indiferentemente literatura, escritura ou texto" [Lc, p. 17, 16 e 17]). 
É que "o texto é atópico, senào no seu consumo, pelo menos na sua produção". É também, que, na guerra das linguagens, pode haver momentos tranqüilos e esses momentos sào textos" (PT, p. 49), pois,

"[...] nesse concerto de pequenas dominaçòes, o Texto [...] apareceu como o próprio índice do despoder. O Texto contém em si a força que permite fugir infinitamente da palavra gregária (aquela que se agrega), mesmo quando ela busca reconstituir-se nele; ele repele sempre para mais longe - e é esse movimento de miragem que tentei descrever e justificar há pouco, falando em literatura —, ele repele para outro lugar, um lugar não classificado, atópico, se é que se pode assim dizer, longe dos topoi da cultura politizada, "esta obrigaçào de formar conceitos, espécies, formas, fins, leis... esse caso dos mundos idênticos”, de que fala Nietzsche; o texto levanta, fraca, transitoriamente, a camada de generalidade, de moralidade, de in-diferença (separemos bem o prefixo do radical) que pesa sobre nosso discurso coletivo" (Lç, p. 34).

Em resumo e finalmente, o texto é o único lugar onde se pode "ouvir a língua fora do poder, no esplendor de uma revoluçào permanente da linguagem" (Lç, p. 16). 


\section{Obras de Roland Barthes e abreviações utilizadas}

BL: Le Bruissement de la langue (Essais iritiques IV). Paris: Le Seuil, 1984. Ediçào portuguesa: O rumor da língua. Trad. Antônio Gonçalves. Lisboa: Ed. 70, col.m "Signos", s.d. Ediçào brasileira: O rumor da lingua. Trad. Mario Laranjeira. Prefácio de Leyla Perrone-Moisés. Sào Paulo: Brasiliense, 1988.

GV: Le Grain de la voix - Entretiens 1962-1980. Paris: Le Seuil, 1981. Edição portuguesa: O grão da voz - Entrevistas 1962-1980. Trad. Teresa Meneses e Alexandre Melo. Lisboa: Ed. 70, col. "Signos", s.d. [1982?].

Lç: Leçon. Paris: Le Seuil, 1978.

Ediçào portuguesa: Lição. Trad. Ana Mafalda Leite. Lisboa: Ed. 70, col. "Signos", s.d. [1979].

Edição brasileira: Aula. Traduçào e posfácio de Leyla Perrone-Moisés. Sào Paulo: Cultrix, 1980.

My: Mythologies. (1957) Paris: Le Seuil, coll. "Points", 1970.

Ediçào brasileira: Mitologias. Trad. Rita Buongermino e Pedro de Souza. Sào Paulo: Difel, 1982.

PT: Le Plaisir du texte. Paris: Le Seuil, coll. "Tel quel", 1973.

Ediçào portuguesa: O pražer do texto. Trad. Maria Margarida Barahona. Prefácio de Eduardo Prado Coelho. Lisboa: Ed. 70, col. "Signos", s.d. [1974].

Ediçào brasileira: O pražer do texto. Trad. Jacó Guinsburg. Sào Paulo: Perspectiva, 1977.

\section{Outros autores}

ALTHUSSER, Louis. "Idéologie et appareils idéologiques d'État (notes pour une recherche)". La Pensée, no 151. Paris, mai-juin 1970.

FOUCAULT, Michel. L'Ordre du discours. Paris: Gallimard, 1971.

MARX, Karl. Le 18-Brumaire de Louis Bonaparte. In: MARX, Karl; ENGELS, Friedrich. Euures choisies, en trois volumes. Vol. 1. Moscou: Éd. du progrès, 1976.

PERRONE-MOISÉS, Leyla. Roland Barthes: o saber com sabor. $2^{a}$ ed. Sào Paulo: Brasiliense, col. "Encanto Radical”, 1985. 